\title{
Clinical course and seroprevalence of COVID-19 in children with rheumatic diseases. Cross-sectional study from a reference centre in Spain.
}

Clara Udaondo ( $\nabla$ clara.udaondo@gmail.com )

La Paz University Hospital: Hospital Universitario La Paz https://orcid.org/0000-0001-6223-7140

Claudia Millan-Longo

La Paz University Hospital: Hospital Universitario La Paz

Celia Permuy

La Paz University Hospital: Hospital Universitario La Paz

\section{Laura Valladares}

La Paz University Hospital: Hospital Universitario La Paz

Iker Falces-Romero

La Paz University Hospital: Hospital Universitario La Paz

Celia Muñoz

La Paz University Hospital: Hospital Universitario La Paz

Monica Morales-Higuera

La Paz University Hospital: Hospital Universitario La Paz

\section{Rosa Alcobendas}

La Paz University Hospital: Hospital Universitario La Paz

\section{Agustin Remesal}

La Paz University Hospital: Hospital Universitario La Paz

\section{Sara Murias}

La Paz University Hospital: Hospital Universitario La Paz

\section{Cristina Calvo}

La Paz University Hospital Biomedical Research Foundation: Fundacion Investigacion Biomedica Del Hospital Universitario La Paz

\section{Research Article}

Keywords: COVID 19, children, rheumatic diseases, corticosteroids, biologic treatment

Posted Date: May 14th, 2021

DOI: https://doi.org/10.21203/rs.3.rs-505561/v1 
License: (c) (i) This work is licensed under a Creative Commons Attribution 4.0 International License. Read Full License 


\section{Abstract}

\section{Background}

Patients with rheumatic diseases have been considered at risk of COVID-19. A significant percentage of infections in children are asymptomatic or mild and can go unnoticed. This study aims to describe the seroprevalence of SARS-CoV-2 in a cohort of children with rheumatic diseases and assess possible risk factors.

\section{Methods:}

A cross-sectional study was performed in a pediatric rheumatology unit from a reference hospital in Madrid, from September 2020 to February 2021. Serology of SARS-CoV-2 was performed at the same time as their routine laboratory tests, and a specific questionnaire was completed by parents. Demographics, treatment and disease activity from laboratory-confirmed COVID-19 patients were compared to the data of patients without laboratory-confirmed COVID-19.

\section{Findings}

A total of 105 children were included. SARS-CoV-2 infection was demonstrated in 27 patients (25.7\%): 6 PCR and 21 positive IgG serology. The mean age was 11.8 years, and the majority of the patients were females $(72.4 \%)$. Most of the children were diagnosed with juvenile idiopathic arthritis (JIA) $(70.3 \%$; 19/27), followed by PFAPA (11.1\%; 3/27). Immunosuppresive treatment was given in $88 \%$ of cases $(24 / 27)$. Overall, $44.4 \%(12 / 27)$ of infected patients were asymptomatic. Three patients required hospital admission because of COVID-19, however none of them required oxygen supplementation. A total of $66.7 \%(18 / 27)$ of patients did not require any treatment or medical assistance. The seroprevalence in our cohort was $20 \%$ in contrast to the $7.7 \%$ population seroprevalence observed during the same study period in Spanish children.

SARS-CoV-2 confirmed children with positive IgG or PCR were less frequently in remission ( $52 \%$ vs $72 \%$; $p$ 0.014). Moderate disease activity and treatment with oral corticosteroids were associated with higher risk for COVID-19 (OR 5.05; Cl 95\%: 1.56 - 16.3 and OR 4.2; Cl 95\%: 1.26 - 13.9 respectively).

\section{Conclusions}

In a cohort of pediatric patients with rheumatic disease and immunosuppressive therapy, moderate disease activity and oral corticosteroids were associated with COVID-19 positive patients. Seroprevalence was significantly higher compared to the same age healthy population. The clinical manifestations were mild and there were no severe infections among the patients.

\section{Introduction}


SARS-CoV-2 is responsible for the COVID-19 pandemic that has spread at a global level in the year 2020 . Disease in children is relatively mild, representing $10 \%$ of identified cases (1), with only a small proportion that require hospitalization. However, a significant percentage of infections in children are asymptomatic or mild and can go unnoticed.

Rheumatic disease (RD) could be considered as a risk factor for COVID-19, due to complications related to the viral disease, possible disease flare during and after SARS-CoV-2 infection, presence of comorbidities and immunosuppressive treatment $(2,3)$. Poorly controlled active RD or certain pharmaceutical agents such as corticosteroids may increase the risk of infection and serious disease. However, immune-mediated inflammatory disease and the use of TNF inhibitors are not associated with a worse clinical outcome (4-6).

Little is known about SARS-CoV-2 infection in children with RD. Small case series show that the disease evolution in hospitalized patients is moderately favourable, although one fatality has been reported (79). Data about the course of mild or asymptomatic infections in children are scarce. We aimed to investigate the seroprevalence and clinical course of COVID-19 in a cohort of pediatric patients with rheumatic diseases and compare laboratory-confirmed COVID-19 patients versus patients without laboratory-confirmed COVID-19.

\section{Methods}

A cross-sectional study was performed including all pediatric patients with rheumatic diseases in a rheumatology unit of a reference hospital in Madrid, Spain, from September 2020 to February 2021. Serology of SARS-CoV-2 (chemiluminescence) was performed at the same time as their routine laboratory tests, and a specific questionnaire was completed by parents. In case of fever or respiratory symptoms, PCR for SARS-CoV-2 was performed according to hospital protocols. Demographics, disease activity, COVID-19 related symptoms, and contact history data were obtained. Children were divided into 3 groups according to disease activity during COVID-19 symptoms or during of the performed SARS-CoV-2 serology: remission (with or without treatment), mild disease activity, and moderate/high disease activity. Seroprevalence (SARS-CoV-2 positive IgG) was compared to the general pediatric population estimates from a governmental COVID-19 health database (last update available from December 2020). Demographics, treatment and disease activity from laboratory-confirmed COVID-19 patients were compared to the data of patients without laboratory-confirmed COVID-19.

Values were expressed as percentages for discrete variables or as mean and standard deviation for continuous variables. Median and interquartile ranges were used for nonparametric variables.Continuous variables were compared using the Student $t$ test or non parametric tests, where appropriate. Categorical variables were compared by the $\chi 2$ test and Fisher exact test. A 2-sided value of $P<0.05$ was considered statistically significant. Allanalyses were performed using the Statistical Package for the Social Sciences (SPSS, IBM. Version 21.0,IBM Corp, Armonk, NY). 


\section{Results}

Overall, 105 pediatric patients with rheumatic diseases were included. Mean age was 11.8 years old (SD 4.5), and the majority of the patients were females (72.4\%). Detailed description of the study cohort is shown in table 1. SARS-CoV-2 infection was confirmed in 27 patients (25.7\%): 6 positive PCR and $21 \mathrm{IgG}$ serology. Most of the children were diagnosed with juvenile idiopathic arthritis (JIA) $(70.3 ; 19 / 27)$, followed by PFAPA (11.1\%;3/27), Lupus $(7.4 \% ; 2 / 27)$, uveitis $(3.7 \% ; 1 / 27)$, vasculitis $(3.7 \% ; 1 / 27)$ and STAT3 gain of function $(3.7 \% ; 1 / 27)$. A total of $23 / 27(85 \%)$ received immunosuppressive therapy and $13 / 27$ (48\%) were in clinical remission. The seroprevalence (positivity of SARS-CoV-2 IgG antibodies) was $20 \%(21 / 105)$ in our cohort. Of six patients with positive PCR, five had negative antibodies and one had indeterminate serology.

The most frequent clinical manifestation for COVID-19 was fever or a low-grade fever (11/27, 41\%). Other frequent findings were headache $(18.5 \% ; 5 / 27)$, odynophagia $(18.5 \% ; 5 / 27)$, gastrointestinal symptoms $(11 \% ; 3 / 27)$, and anosmia/ageusia $(11 \% ; 3 / 27)$. A total of $44.4 \%(12 / 27)$ of infections were asymptomatic. Three patients required hospital admission; none of them needed oxygen supplementation or intensive care unit admission. One patient with PFAPA was admitted because of Multisystemic Inflammatory Syndrome (MIS-C) suspicion which was not confirmed. The other two were a patient with antiphospholipid syndrome and lupus onset with deep vein thrombosis, and a patient with vasculitis admitted for observation. Overall, $66.7 \%$ (18/27) of cases did not require any treatment or medical assistance. Among the patients in the study, 59.3\% (16/27) had close contact with an individual with confirmed COVID-19.

We compared the baseline characteristics of patients with laboratory-confirmed SARS-CoV-2 and found a significantly lower percentage of patients in clinical remission ( $52 \%$ vs $72 \%, \mathrm{p} 0.014$ ) and a higher percentage of patients with moderate-high disease activity ( $30 \%$ vs $8 \%, p$ 0.007). Oral corticosteroids were higher in patients diagnosed with COVID-19 (30\% vs $8 \%$, p0.036). Patients with moderate/high disease activity were five times more likely to test positive for SARS-CoV-2 (Odds ratio (OR) 5.05, Cl 95\%: 1.56-16.3). The OR for testing positive for SARS-CoV-2 in patients treated with oral corticosteroids was 4.2 (Cl 95\%: 1.26-13.9).

\section{Discussion}

Studies of SARS-CoV-2 infection in children with RD are scarce. We have demonstrated a high seroprevalence $(20 \%)$ in this group of patients, with the majority having mild infections. To the best of our knowledge, this is the first study of seroprevalence in this patient population, which tested both children with and without suspected COVID-19. Most infections were mild; more than $1 / 3$ being asymptomatic and $2 / 3$ did not require any medical assistance.

The severity of our cases is similar to that described in the literature $(7,8,10)$. Ihara et al retrospectively described 14 COVID-19 confirmed cases in pediatric patients with RD, reporting mild to moderate 
symptoms and no complications. Seroprevalence in their cohort was 2,2\%, although testing was performed only in symptomatic cases, so asymptomatic infections were left undetected (11).

Seropositivity for SARS-CoV-2 was $20 \%$ in our cohort. According to a national registry, seroprevalence for SARS-CoV-2 infection in Spain during the same study period (December 2020) was $12.5 \%$ in adults and $7.7 \%$ in children (12). The higher seroprevalence in our cohort could be partially explained by the high percentage of asymptomatic infections. Preliminary evidence suggests that children are just as likely to become infected with SARS-CoV-2 as are adults, but are less likely to be symptomatic or develop severe symptoms (13). Another possible explanation to this higher seroprevalence could be that children with rheumatic diseases have a higher exposure due to frequent hospital visits than healthy children. Also, there could be a negative selection bias in other seroprevalence studies, since healthy children are less likely to voluntarily undergo invasive tests such as blood tests as required for serology. Nevertheless, new studies are needed to elucidate this higher seroprevalence.

Children with active disease and corticosteroid treatment had a higher risk of SARS-CoV-2 infection, similarly to that described in adults with RD $(4,5,8)$. High disease activity is a significant risk factor for an increased rate of infectionsboth in children and adult patients with $\operatorname{RD}(14,15)$ In our study, children with moderate to high disease activity were five times more likely to test positive for SARS-CoV-2. Likewise, those treated with oral corticosteroids were four times more likely than those children who were not receiving oral corticosteroids.

The question about whether immunosuppressive treatment should be discontinued in these patients is a major concern for clinicians (16). Biologic therapy, specially TNF inhibitors, do not appear to be a risk factor for COVID-19 in adult patients $(4,6,10)$. Marino et al. reported four cases of COVID-19 in JIA adult and pediatric patients receiving TNF inhibitors, however they did not observe severe infections among the four patients. In two patients, disease reactivation likely occurred due to drug discontinuation (19). A recent survey among pediatric rheumatologists indicates that $>94.2 \%$ of the respondents would not support a preventive adaptation of the immunomodulating therapy in children with COVID-19 (20). Based on previous case series, scientific associations have released recommnendations for managing these patients (21-25). In our study, all patients continued their treatments without any preventive adaptation. Although it seems safe to consider these patients risky while taking precautions, our findings support the hypothesis that an adaptation of the immunosuppressive maintenance treatment may not be necessary.

\section{Conclusions}

In a cohort of pediatric patients with rheumatic diseases, SARS-CoV-2 infection was demonstrated in $25.7 \%$ of cases. Seroprevalence was $20 \%$, significantly higher compared to the same age healthy population according to national studies. The clinical course was mild, with one-third of asymptomatic cases. Severe infections were not observed among the patients. Disease activity and the use of oral corticosteroids appear to be risk factors for laboratory-confirmed COVID-19. Children with rheumatic disease in clinical remission may not be considered as a risk population for severe COVID-19. 


\section{List Of Abbreviations}

JIA : Juvenile Idiopatic arthritis

PFAPA: Periodic Fever, Adenopathy, Pharyngitis and Aphthous stomatitis

$\mathrm{RD}$ : Rheumatic Disease

PCR: Polimerase Chain Reation

MIS-C: Multisystemic Inflammatory Syndrome

\section{Declarations}

Ethics approval and consent to participate: This study was approved by the ethics committee of Hospital La Paz (code PI-4457). Informed consent was obtained by parents and mature minors.

Consent for publication: not applicable.

Availability of data and materials: The datasets used and/or analysed during the current study are available from the corresponding author on reasonable request.

Competing Interests: The authors declare that they have no competing interests.

Funding: No funding was received.

Author's contributions: CU had primary responsiblity for protocol development, patient screening, enrollment, outcome assessment, preliminary data analysis and writing the manuscript. CML, $C M, M M H$, RA, AR, SM, IFR, CP and LV participated in patient screening, the development of the protocol and analytical framework for the study and contributed to the writing of the manuscript. CC performed the final data analyses and was a major contributor in writing the manuscript. All authors read and approved the final version.

\section{Acknowledgments:}

Kinga Sandor Bajusz

\section{References}

1. Sisk B, Cull W, Harris JM, Rothenburger A, Olson L. National Trends of Cases of COVID-19 in Children Based on US State Health Department Data. 2020 [cited 2021 Apr 27]; Available from: https://doi.org/10.1542/peds.2020-027425.

2. Hasseli R, Mueller-Ladner U, Schmeiser T, Hoyer BF, Krause A, Lorenz HM, et al. National registry for patients with inflammatory rheumatic diseases (IRD) infected with SARS-CoV-2 in Germany 
(ReCoVery): A valuable mean to gain rapid and reliable knowledge of the clinical course of SARSCoV-2 infections in patients with IRD. RMD Open [Internet]. 2020 Sep 2 [cited 2021 May 5];6(2). Available from: https://pubmed.ncbi.nlm.nih.gov/32878994/.

3. Xu C, Yi Z, Cai R, Chen R, Thong BYH, Mu R. Clinical outcomes of COVID-19 in patients with rheumatic diseases: A systematic review and meta-analysis of global data [Internet]. Autoimmunity Reviews. Elsevier B.V.; 2021 [cited 2021 Apr 27]. Available from: https://doi.org/10.1016/j.autrev.2021.102778.

4. Gianfrancesco M, Hyrich KL, Hyrich KL, Al-Adely S, Al-Adely S, Carmona L, et al. Characteristics associated with hospitalisation for COVID-19 in people with rheumatic disease: Data from the COVID-19 Global Rheumatology Alliance physician-reported registry. Ann Rheum Dis [Internet]. 2020 Jul 1 [cited 2021 Apr 24];79(7):859-66. Available from: /pmc/articles/PMC7299648/.

5. Nuño L, Novella Navarro M, Bonilla G, Franco-Gómez K, Aguado P, Peiteado D, et al. Clinical course, severity and mortality in a cohort of patients with COVID-19 with rheumatic diseases [Internet]. Vol. 79, Annals of the Rheumatic Diseases. BMJ Publishing Group; 2020 [cited 2021 May 3]. p. 1659-61. Available from: /pmc/articles/PMC7677491/.

6. Michelena X, Borrell H, López-Corbeto M, López-Lasanta M, Moreno E, Pascual-Pastor M, et al. Incidence of COVID-19 in a cohort of adult and paediatric patients with rheumatic diseases treated with targeted biologic and synthetic disease-modifying anti-rheumatic drugs. Semin Arthritis Rheum [Internet]. 2020 Aug 1 [cited 2021 Mar 11];50(4):564-70. Available from: /pmc/articles/PMC7229730/.

7. Yildiz M, Haslak F, Adrovic A, Sahin S, Barut K, Kasapcopur O. The frequency and clinical course of COVID-19 infection in children with juvenile idiopathic arthritis. Vol. 38: Clinical and experimental rheumatology. NLM (Medline); 2020. pp. 1271-2.

8. Calvo C, Udaondo C. COVID-19 in Children With Rheumatic Diseases in the Spanish National Cohort EPICO-AEP. J Rheumatol [Internet]. 2021 Feb 1 [cited 2021 Apr 27];jrheum.201548. Available from: www.jrheum.org.

9. Quintana-Ortega C, Remesal A, Ruiz de Valbuena M, de la Serna O, Laplaza-González M, ÁlvarezRojas E, et al. Fatal outcome of anti-MDA5 juvenile dermatomyositis in a paediatric COVID-19 patient: a case report. Mod Rheumatol Case Reports [Internet]. 2021 Jan 2 [cited 2021 May 5];5(1):101-7. Available from: https://pubmed.ncbi.nlm.nih.gov/33019894/.

10. Demir F, Ulu K, Çağlayan Ş, Coşkuner T, Sözeri B. Clinical course of COVID-19 in children with rheumatic disease under biologic therapy. Vol. 39: Clinical and experimental rheumatology. NLM (Medline); 2021. pp. 36-7.

11. Ihara BP, Strabelli CAA, Simon JR, Viana VSL, Sallum AME, Kozu KT, et al. Laboratory-confirmed pediatric COVID-19 in patients with rheumatic diseases: A case series in a tertiary hospital [Internet]. Vol. 30, Lupus. SAGE Publications Ltd; 2021 [cited 2021 Apr 27]. p. 856-60. Available from: http://journals.sagepub.com/doi/10.1177/0961203321998427. 
12. Pollán M, Pérez-Gómez B, Pastor-Barriuso R, Oteo J, Hernán MA, Pérez-Olmeda M, et al. Prevalence of SARS-CoV-2 in Spain (ENE-COVID): a nationwide, population-based seroepidemiological study. Lancet. 2020 Aug;22(10250):535-44. 396(.

13. Zimmermann P, Curtis N. Coronavirus infections in children including COVID-19: An overview of the epidemiology, clinical features, diagnosis, treatment and prevention options in children [Internet]. Vol. 39, Pediatric Infectious Disease Journal. Lippincott Williams and Wilkins; 2020 [cited 2021 Apr 27]. p. 355-68. Available from: /pmc/articles/PMC7158880/.

14. Au K, Reed G, Curtis JR, Kremer JM, Greenberg JD, Strand V, et al. High disease activity is associated with an increased risk of infection in patients with rheumatoid arthritis. Ann Rheum Dis [Internet]. 2011 May 1 [cited 2021 May 6];70(5):785-91. Available from: https://ard.bmj.com/content/70/5/785.

15. Deniz Batu E, Özen S. Implications of COVID-19 in pediatric rheumatology. Rheumatol Int [Internet]. 2020;40:1193-213. Available from: https://doi.org/10.1007/s00296-020-04612-6.

16. Deniz Batu E, Lamot L, Sag E, Ozen S, Uziel Y. How the COVID-19 pandemic has influenced pediatric rheumatology practice: Results of a global, cross-sectional, online survey. 2020 [cited 2021 Apr 27]; Available from: https://doi.org/10.1016/j.semarthrit.2020.09.008.

17. Marino A, Romano M, Gattinara M, Cimaz R. Patients with juvenile idiopathic arthritis on TNF inhibitors exposed to COVID-19 family members. Vol. 50: Seminars in Arthritis and Rheumatism. W.B. Saunders; 2020. pp. 1214-5.

18. Janda A, Schuetz C, Canna · Scott, Gorelik M, Heeg M, Minden K, et al. Therapeutic approaches to pediatric COVID-19: an online survey of pediatric rheumatologists. Rheumatol Int [Internet]. 2021 [cited 2021 Apr 27];41:911-20. Available from: https://doi.org/10.1007/s00296-021-04824-4.

19. Wahezi DM, Lo MS, Rubinstein TB, Ringold S, Ardoin SP, Downes KJ, et al. American College of Rheumatology Guidance for the Management of Pediatric Rheumatic Disease During the COVID-19 Pandemic: Version 1. Arthritis Rheumatol [Internet]. 2020 Nov 1 [cited 2021 Apr 27];72(11):1809-19. Available from: https://onlinelibrary.wiley.com/doi/10.1002/art.41455.

20. Schulze-Koops H, Iking-Konert C, Leipe J, Hoyer BF, Holle J, Moosig F, et al. Recommendations of the German Society for Rheumatology for management of patients with inflammatory rheumatic diseases in the context of the SARS-CoV-2/COVID-19 pandemic - Update July 2020 [Internet]. Vol. 79, Zeitschrift fur Rheumatologie. Springer Medizin; 2020 [cited 2021 May 5]. p. 679-85. Available from: https://pubmed.ncbi.nlm.nih.gov/32757030/.

21. European League Against Rheumatism (EULAR). EULAR Guidance for patients COVID-19 outbreak. Available from: https://www.eular.org/eular_guidance_for_pa- tients_covid19_outbreak.cfm. [Accessed May 1 2021].

22. National Institute for Health and Care Excellence (NICE). COVID-19 rapid guide- line: rheumatological autoimmune, inflammatory and metabolic bone disorders (NG167). Available from: https://www.nice.org.uk/guidance/ng167. [Accessed May 1 2021]. 
23. Paediatric Rheumatology European Association (PRES). PRES recommendations for coronavirus outbreak. Available from: https://www.pres.eu/news/newsstory. html?id = 29. [Accessed May 1 2021].

\section{Tables}

Table 1. Baseline characteristics of children with rheumatic diseases who tested positive or negative for SARS-CoV-2.

\begin{tabular}{|c|c|c|c|}
\hline & SARS-CoV-2 positive & SARS-CoV-2 negative & $p$ \\
\hline$n$ & 27 & 78 & 105 \\
\hline Age & $11.7( \pm 4.7 \mathrm{SD})$ & $11.8( \pm 4.5 \mathrm{SD})$ & \\
\hline Ethnicity: caucasic & $25 / 27(92 \%)$ & $74 / 78(95 \%)$ & \\
\hline Gender: female & $19 / 27(70 \%)$ & $57 / 78(73 \%)$ & 0.80 \\
\hline Living in Madrid & $21 / 27(78 \%)$ & $61 / 78(78 \%)$ & 0.57 \\
\hline \multirow[t]{3}{*}{ Diagnosis } & IIA 19/27 (70\%) & UIA 55/79 (70\%) & 0.82 \\
\hline & Periodic fever $3 / 27$ (11\%) & Periodic fever $4 / 78$ (5\%) & \\
\hline & $\begin{array}{l}\text { Connective tissue disease } \\
2 / 27(7 \%) \\
\text { Uveitis } 1(4 \%) \\
\text { Other } 2(7 \%)\end{array}$ & $\begin{array}{l}\text { Connective tissue disease } \\
10 / 78(13 \%) \\
\text { Uveitis } 5(6 \%) \\
\text { Other } 4(5 \%)\end{array}$ & \\
\hline $\begin{array}{l}\text { Immunosuppressive } \\
\text { therapy* }\end{array}$ & & & 0.15 \\
\hline None & 6/27 (22\%) & $10 / 78(12.8 \%)$ & \\
\hline Methotrexate & - & $10 / 78(12.8 \%)$ & \\
\hline Biologic & $18 / 27(67 \%)$ & $49 / 78(63 \%)$ & \\
\hline Other & $3 / 27(11 \%)$ & $21 / 78$ & \\
\hline $\begin{array}{l}\text { Oral corticosteroids } \\
\text { Disease activity* }\end{array}$ & $7 / 27(26 \%)$ & $6 / 78(8 \%)$ & 0.036 \\
\hline Remission & $14 / 27(52 \%)$ & $56 / 78(72 \%)$ & 0.014 \\
\hline Mild activity & $5 / 27(18 \%)$ & $16 / 78(20 \%)$ & \\
\hline Moderate/high & $8 / 27(30 \%)$ & 6/78 (8\%) & 0.007 \\
\hline
\end{tabular}

*At the time of COVID-19 diagnosis or at the time of serology of SARS-CoV-2 in absence of a COVID-19 diagnosis. 